\title{
Role and challenge of rural banks in the financial inclusive growth of India
}

\author{
N. Karunakaran \\ ${ }^{1}$ Principal and Research Guide in Economics of Kannur University, Dept. of Economics, People Institute of Management Studies, \\ Kasaragod, Kerala, India, \\ *Corresponding Author: N. Karunakaran \\ Email: narankarun@gmail.com
}

\begin{abstract}
Financial inclusion is delivery of banking services at a cheaper cost to the vast sections of under privileged and low income groups. An inclusive financial system can help in reducing the growth of informal sources of credit such as money lenders, which are often found to be exploitative. The performance of the Indian economy is one of the strongest drivers for the banking industry's growth and vice versa. This represents a massive opening that financial institutions in the country can leverage upon for future growth.
\end{abstract}

Keyword: Financial inclusion, Financial institution, Informal source of credit.

\section{Introduction}

Financial inclusion is the availability of banking services at an affordable cost to the disadvantaged and low income groups. In India, the basic concept of financial inclusion is having a saving or current account at any bank. In reality, it includes loans, insurance services and much more, for all members of an economy. An inclusive financial system has several merits. It facilitates efficient allocation of productive resources and thus can potentially reduce the cost of capital. In addition, access to appropriate financial services can significantly improve the day to day management of finance.

\section{Methods and Materials}

A systematic search was conducted to understand the broad issues on the role and challenges of Rural Banks in the financial inclusive growth of India. Important reports and articles were used for reference.

\section{Results}

\section{Regional Rural Banks (RRBs)}

In India it is an integral part of the rural credit structure. RRBs were established under the provisions of an ordinance promulgated on 26th Sept. 1975 and the RRB Act, 1976 with an objective to ensure sufficient institutional credit for agriculture and other rural sectors. The RRBs mobilize financial resources for rural / semi-urban areas and grant loans and advances mostly to small and marginal farmers, agricultural labourers and rural artisans. The area of operation of RRBs is limited to the area as notified by Govt. of India covering one or more districts in the state. RRBs are jointly owned by Govt. of India (GOI), the concerned State Government and sponsor banks.

\section{Reform Process of RRBs}

The GOI initiated the process of structural consolidation of RRBs by amalgamating RRBs sponsored by same bank within a state as per the recommendations of the Vyas Committee in the year 2004. The amalgamated RRBs were expected to provide better customer service due to better infrastructure, computerization of branches, pooling of experienced workforce, publicity, marketing efforts and also derive the benefits of a large area of operation, enhanced credit exposure limits and diverse banking activities.

\section{Financial inclusion through regional rural bank}

Financial access will attract global market players to our country and that will result in increasing employment and business opportunities. Inclusive growth will act as a source of empowerment and allow people to participate more effectively in the economic and social process. There are 14,475 rural banks in the country of which $2126(91 \%)$ are located in remote rural areas. According to a working paper from the Reserve Bank of India, in the group of 23 states for which a 3-dimensional Index of Financial Inclusion (IFI) has been estimated by using data on 3 dimensions of financial inclusion, Kerala leads with the highest value of Index of Financial Inclusion (IFI). Kerala was the first state to declare Total financial inclusion.

\section{Importance of Financial inclusion through RRBs}

Financial inclusion is a policy measure to address the issue of poverty which would ensure avenues for people. It is estimated that globally over two billion people are excluded from access to financial services, of which one third is in India. Access to various financial services enables the poor people to participate in the growth of the economy. Many banks are forced to adopt financial inclusion rather than their own interest. Only few banks are actively involved in financial inclusion to promote economic development. The banks have encountered various problems while adopting financial inclusion, Viz, Improper repayment, the need for additional workforce, more time consumption, heavy work load, high cost etc. Hence, many banks are not fostering fully fledged financial inclusion plan to accelerate the growth of the country.

\section{RRBs and the emerging architecture for banking services in rural areas}

The differentiation could be on account of capital requirement, scope of activities or area of operations. In fact the UCBs, the PACS, the RRBs and LABs could be considered to be differentiated banks as they operate in 
localized areas. To tap the unmet demand for financial services, it is felt that it is worth experimenting with new types of institutions for financial inclusion. A question arises how the activities of these entities with overlapping functions and clientele as RRBs would impact on their relevance and viability.

\section{RRB's progress under financial inclusion through different variables 2013-2017}

The RRB's progress in terms of banking outlets in villages' variable shows positive result from 2013 to 2016 and in 2017 there is slight decrease in the number of branches opened. From 2013 to 2017 many branches have been opened and it is the sign of unbanked people are included in banking system under financial inclusion. At the same time branchless mode branches are more in number from 2013 to 2017 . If there is no specific branch through BC's or of other banking service, many branchless mode outlets of RRB have shown positive growth. As per different variables, progress report of RRB's there is more number of $\mathrm{KCC}$ and GCC issued to the accounts holders and through ICT many transactions have been increased since 2013. Hence the objective of financial inclusion through RRBs in India shows positive trend.

\section{Success of RRBs}

The rapid expansion of $\mathrm{RRB}$ has helped in reducing substantially the regional disparities in respect of banking facilities in India. The efforts made by RRB in branch expansion, deposit mobilization, rural development and credit deployment in weaker section of rural areas are appreciable. RRB has successfully achieved its objectives by taking banking to door steps of rural households, particularly in banking deprived rural areas, to avail easy and cheaper credit to weaker rural section that are dependent on private lenders, to encourage rural savings for productive activities, to generate employment and to bring down the cost of purveying credit in rural areas.

Thus, RRBs are providing the strongest banking network and the Government should take effective remedial steps to make rural banks viable. As per the recent achievement they have not fully utilized their potential, especially in the area of credit disbursement. The creation of a range of banking entities appears to crowd into the space presently being occupied by the RRBs. Initiatives such as the amendment to the RRB Act, that seek to create a role for private players in RRB ownership appear to have been pushed through, without a wider consultation and consideration of alternative options. Calls for further amalgamation of RRBs to the state level, also can contribute to further distancing them from their original mandate.

\section{Sustainable Development through Financial Inclusion}

RRB's is an important player in Indian financial System because of penetration and the increasing amount of loans and customers. The dream of inclusive growth is still a dream but will be overcome with continual growth of RRBs and effective financial services. RRBs serve the backward section of the society, the rural poor and people belonging to the lower income group. These banks play a significant role in ensuring sustainable development.

\section{RRBs Outstanding issues and policy imperatives \\ The following major issues need to be addressed}

RRBs to scale-up through privatization and further rounds of amalgamation to be moved up in the financial value chain. If so, how is that going to affect their ability to serve their original mandate? How are the emerging entities such as small banks, MUDRA and payment banks positioned in relation to RRBs, now and in the future?

The viability of RRBs: Is there a need for a modified view to implement strategies of cross subsidization and even more ambitious and alternative accounting frame that takes into account their special charter and area of operations? From the point of view of sustainability RRBs want to be allowed to expand their non-priority sector portfolio as well in view of the asset concentration risk and other low profitability. However, RBI does not allow them to open branches in urban areas.

Investment issues: RRBs, instead of focusing on lending are content to place funds mobilized through deposits in government and PSU bonds and with their sponsor banks, often in excess of the statutory liquidity ratio. As a result RRBs' investments in government securities and PSU bonds and debentures have increased while they have been hesitant to augment their loan portfolios. What incentives can be created to break this phenomenon and the dependence on sponsorship banks for off-take of the RRBs' investment funds?

Human Resource Issues: The constant refrain in both the literature as well as from the field is about the two-fold effect of the HR factor, of how the high wage structures are determined by commercial bank rates and skills and nature of personnel are not appropriate for the banking business undertaken by RRBs.

Technology: A host of technological applications await introduction in the banking system, and with the inevitable time lag, with the RRBs. A case in point is the RBI clearance for mobile applications to be used by RRBs.

Finally, regarding Financial Inclusion, while a host of measures and products have been introduced by different RRBs given their strengths and sponsor bank initiatives, an important client has been given short shrift in the quest for profitability. SHGs constitute a natural partner for RRBs badly in need of sustenance. However, what may be required is the development of a critical mass of SHGs in each area, which permits large-scale operations and economies of scale. For this, the support of NRLM and NABARD, as part of a multi-pronged effort could provide the answer. It could also lead on to further scaling up of financial services, as larger lively hood efforts are undertaken. Related to financial inclusion is another important area, that of the BC model, the 
viability of which is still open to question and renewed efforts need to be made to generate an appropriate business model.

Future Challenges for Regional Rural Banks: Even after the positive findings that RRB's are successful in achieving the objective of financial inclusion to a great extent, still they have to overcome the following challenges to the path of Financial Inclusion:

All backward sections and informal sectors should be included up to a large extent

Rural people are not much aware of financial inclusion because of illiteracy and the access to financial services should be increased.

People consider that financial services are costly and access is difficult because of the several reasons and this thought needs to be addressed.

\section{Conclusion}

RRBs play a key role as an important vehicle of credit delivery in rural areas with the objective of credit dispersal to small, marginal farmers and socio-economically weaker section of population for the development of agriculture, trade and industry. But still its commercial viability has been questioned due to its limited business flexibility, smaller size of loan and high risk in loans and advances. Rural banks need to remove lack of transparency in their operation which leads to unequal relationship between banker and customer, the banking staff should interact more with their customers to overcome this problem and should open their branches in areas where customers are not able to avail banking facilities. In this competitive era, RRBs have to concentrate on speedy, qualitative and secure banking services to retain existing and attract potential customers.

\section{Source of Funding}

None.

\section{Conflict of Interest}

None.

\section{References}

1. Bhargava AS. "Kerala set to achieve $100 \%$ financial inclusion” Business Line. 2011.

2. Misra BS. The Performance of Regional Rural Banks (RRBs) in India: Has Past Anything to Suggest for Future?" ' Reserve Bank of India Occas Papers, 2006;27:1,2, Summer and Monsoon.

3. Ghorude KN. "Micro Finance for Financial Inclusion and Sustainable Rural Development", Southern Economist. 2009;48(1):47-50.

4. Chakrabarty KC,"Financial Inclusion-A road India needs to travel", Live mint \& The wall street $j .2011$.

5. Muthiah MP, Muthiah K. "Financial Inclusion in the Indian Rural Area Context -A Micro level Study", Res Highlights.2010; 20(2):71-74.

6. Narendra M,"Financial Inclusion Gains Urgency", The Hindu Survey of Indian Industry. 2011.

7. Kapila R, Kapila U. "Inclusive Growth: The Role of Banks in Emerging Economies", Economic Developments in India, Academia Foundation. 2008.

8. Sendhilvelan M, Karthikeyan K. No Frills Account: A Basic Drive for Financial Inclusion", South Economist. 2006;45:13-14.

9. Narayan S. "Fundto Boost Financial Inclusion in the Works", http://news.in.msn. com/business/article.aspx?cpdocumentid=4833211.2011.

10. Usha Thorat. Financial Inclusion -the Indian Experience. Financial Inclusion Conference. London. BIS Rev.2007.

11. Kharur ZH, Manjunatha T. A Study on Financial Inclusion in Indian Regional Rural Banks. 2018.

How to cite: N. Karunakaran. Role and challenge of Rural Banks in the Financial Inclusive Growth of India. J Manag Res Anal. 2020;7(3):104-6. 